\title{
Fermentation as a Strategy for Bio-Transforming Waste into Resources: Lactic Acid Production from Agri-Food Residues
}

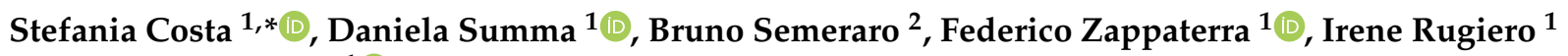 \\ and Elena Tamburini ${ }^{1}$ (D) \\ 1 Department of Life Sciences and Biotechnology, University of Ferrara, Via L. Borsari, 46, 44121 Ferrara, Italy; \\ daniela.summa@unife.it (D.S.); zppfrc@unife.it (F.Z.); irene.rugiero@unife.it (I.R.); tme@unife.it (E.T.) \\ 2 GATE SRL, Via L. Borsari, 46, 44121 Ferrara, Italy; bsemeraro@gategreen.it \\ * Correspondence: stefania.costa@unife.it; Tel.: +39-0532-455-708
}

check for

updates

Citation: Costa, S.; Summa, D.;

Semeraro, B.; Zappaterra, F.;

Rugiero, I.; Tamburini, E.

Fermentation as a Strategy for

Bio-Transforming Waste into

Resources: Lactic Acid Production

from Agri-Food Residues.

Fermentation 2021, 7, 3.

https://dx.doi.org/10.3390/

fermentation7010003

Received: 7 December 2020

Accepted: 22 December 2020

Published: 24 December 2020

Publisher's Note: MDPI stays neutral with regard to jurisdictional claims in published maps and institutional affiliations.

Copyright: () 2020 by the authors. Licensee MDPI, Basel, Switzerland. This article is an open access article distributed under the terms and conditions of the Creative Commons Attribution (CC BY) license (https: / / creativecommons.org/ licenses/by/4.0/).

\begin{abstract}
Lactic acid (LA) obtained by fermentation of carbohydrates is well-known and widely used in the food sector. This process is as an alternative to the chemical synthesis and ensures several advantages especially in terms of environmental sustainability. In particularly, the opportunity to use agro-food residues as fermentable raw materials could improve the overall process sustainability, without considering the indisputable advantages in terms of waste reduction and residual biomass valorization, in a bio- and circular economy perspective. This research deals with the study and development of the fermentation processes of various waste biomasses from the agro-food industries, including milk whey (MW), ricotta cheese whey (RCW), pear processing residues (PPR), potato pomace (PP), tomato pomace (PT), in order to obtain an experimental protocol applicable to the production of LA. Lactobacillus casei DSM 20011 (ATCC 393), a homofermentative L(+)-LA producing bacterium has been used, starting from small-scale tests to verify of the microorganism to grow in complex medium with different carbon sources and the possible presence of potentially toxic substances for microbial growth. Yields from $27.0 \pm 0.3 \%$ to $46.0 \pm 0.7 \%$ have been obtained. Then, a scaling-up was performed in a $1 \mathrm{~L}$ batch fermenter, using a mixed medium of RCW and PPR in different ratio. The best LA yield was $78.3 \%$ with a volumetric productivity of $1.12 \mathrm{~g} / \mathrm{L} \cdot \mathrm{h}$ in less than $60 \mathrm{~h}$.
\end{abstract}

Keywords: lactic acid; PLA; Lactobacillus casei; agri-food waste; circular economy

\section{Introduction}

Agri-food residues refer to organic waste that results from the processing and packaging of animal and/or plant products by the agri-food industry [1]. The Food and Agriculture Organization (FAO) estimates that about one-third of food worldwide produced for human nutrition is yearly lost or wasted [2]. Considering the entire supply chain, including agricultural production, for the EU-27 food waste can be quantified in about 129 million tonnes per year, with about $25 \%$ accounted for the sole postharvest and manufacturing stages [3]. Such a large quantity poses the question of high costs of management for collection and transportation, as well as the need of adequate treatment facilities. In fact, the Directive (EU) 2018/850 requires to reduce to 10\% waste disposal by landfilling and prohibits landfilling for waste that can be recovered in line with the waste hierarchy [4]. In particular, the separate collection of bio-waste and the enhancement of its valorization rates are still a key issue in EU [5]. This ensure that economically valuable waste materials will be reinjected into the EU economy and prevent detrimental consequences for human health and the environment [6].

However, more studies are needed to foster the switch to more sustainable agri-food system and to promote the adoption of circular economy concepts [7]. As it is well known, from a circular economy perspective, bio-waste can become a secondary resource to be valorized in the construction of a new generation of bio-based building blocks [8]. In this 
regard, a key-molecule is 2-hydroxypropanoic acid-better known as lactic acid (LA). Despite its late discovery at the end of the 1700s, this molecule occurs in almost every living organism and it plays an essential role in the anaerobic energy metabolism of billions of life forms [9]. In recent decades, LA has received increasing attention, eventually being identified as one of the highest potential platform chemicals, a short group molecules that are envisioned to bridge nature's abundant polysaccharide feedstock to the production of added-value chemicals and intermediate building blocks [10]. LA has been already used in the food industry as an emulsifying, acidulant, buffering, and preserving agent [11]. Due to its antibacterial and ink-erasure properties, it has also been used in the textile, detergent, and paper industries [12] and over the past few years it has received raising attention as monomer for biodegradable plastics such as polylactic acid (PLA) [13] or as a precursor of acrylic acid (AA) [14]. Currently, LA is starting to win also new market niches related to high value added products, in the pharmaceutical and cosmetic sectors [15].

Lactic acid can be synthetized by chemical synthesis and microbial fermentation. The first results in the production of racemic mixture of LA and involves the production of intermediates that derive from petrochemical sources, leading to environmental negative consequences [16]. On the other hand, over $90 \%$ of the current commercial production of LA is performed by bacteria through anaerobic fermentation of sugars [17]. Today, glucose and sucrose are the main starting resources. Other possible feedstocks are easily hydrolysable poly- or disaccharides derived from corn syrups, molasses, beet extracts, whey, and all kinds of starches [10].

In this context, the use of agriculture and agri-food waste represent an interesting alternative to replace the refined and costly feedstock and the bulk use of such materials will help to solve many environmental hazard [18]. In addition to milk whey and molasses, which are traditionally used in LA fermentation [19], great attention has been focused on cassava bagasse [20], sugar cane bagasse [21], sugar beet pulp [22], coffee husk and pulp [23], apple pomace [24], oil-cakes [25], and wheat/rice bran [26].

There are different processes for biotechnological production of LA. Having viscous and heterogeneous waste as substrate, batch fermentation is the most common approach to produce LA, because it permit the complete substrate depletion, but also continuous flow processes has been developed in order to try overcoming the typical disadvantages of discontinuous methods, such as long lag phase with low productivities and high capital costs, acidification of the medium, and substrate inhibition [27].

LA can be produced by several microorganisms, including wild-type and engineered LA-producing bacteria or genetically-modified yeasts. These organisms can be divided into four main groups, namely, lactic acid bacteria (LAB), Bacillus strains, Escherichia coli, and Corynebacterium glutamicum [28]. LAB are the most common bacteria for the production of LA at industrial scale. Most LAB, including Lactobacilli, are considered to be safe for industrial lactic acid production because they have had a long history of industrial-scale production without adverse health effects on either consumers or production workers. Commercially important LAB strains, such as Lactobacillus strains, i.e., L. delbrueckii spp. bulgaricus, L. casei and L. helveticus, have been particularly useful due to their ability to convert numerous mono- (both hexose and pentose) and di- saccharides, and high tolerance to broad interval of temperature (ranging from 20 to $55^{\circ} \mathrm{C}$ ) and $\mathrm{pH}$ (they can survive at $\mathrm{pH}$ 5 and lower) [29]. Depending on the metabolic pathways, they can produce L- or D-lactic acid (by homo-, hetero-, or mixed-acid fermentation) [30].

The potential L. casei and L. farciminis for LA fermentation of in microaerophilic conditions and mild sterility using pear pomace and ricotta cheese whey (RCW) as single substrate has been evaluated in a previous work [31].

In the present work, the production of optically pure L-LA by a strain of homofermentative L. casei from agri-food waste, without any other nutrients integration and without medium sterilization, has been studied. Organic waste, including milk whey, ricotta cheese whey, pear processing residues, potato pomace, tomato pomace, have been chosen based on the local availability [32], and tested as single and mixed substrates. Microaerophilic batch 
fermentations have been carried out at small-test level (working volume, $100 \mathrm{~mL}$ ) in order to verify the absence of toxic compounds in waste, and then scaled-up in a $1 \mathrm{~L}$ fermenter (working volume, $700 \mathrm{~mL}$ ) where the fermentation conditions were preliminary optimized. Agri-food waste comprises a complex mixture of residues that can have different composition depending on regional and climatic factors. Additionally, agri-food waste is an ideal substrate for proliferation of $\mathrm{LAB}$, and natural growth of $\mathrm{LAB}$ can occur within a wide range of conditions. Nevertheless, this endemic production of LA could become, in some cases, detrimental because of the indigenous production of a racemic mixtures, whereas in some application as the production of PLA, a very high optical purity is demanded. Moreover, horticultural and fruit waste are usually available for short period of the year, corresponding to the months of their harvesting and/or processing. In particular, they are accessible from the late spring to the early fall, differently from wheys that are constantly supplied during all the year. In particular, potato is available from June to July, tomato from late July to early September and pear from September to October.

This research lays the ground for the opportunity of exploit agri-food residues through fermentation to LA, hypothesizing a continuous process where the waste would be progressively added as carbon source, depending on the seasonal availability reducing as much as possible the cost of the process.

\section{Materials and Methods}

\subsection{Microorganism and Culture Conditions}

Lactobacillus casei DSM 20011 (ATCC 393), a homofermentative L(+) lactic acid producing bacterium, belongs to the collection of microorganisms of the Life Sciences and Biotechnology Department of the University of Ferrara and was purchased from the DSMZ (Leibniz Institute DSMZ-German Collection of Microorganisms and Cell Cultures $\mathrm{GmbH})$ company.

The master cell bank is maintained at $-20{ }^{\circ} \mathrm{C}$ in cryovials in a standard De Man, Rogosa and Sharpe (MRS) medium $(1 \mathrm{~mL})$ mixed with glycerol $(0.5 \mathrm{~mL})$ as crioprotective agent. The standard MRS medium (Fluka Analytical, Bucks, switzerland) contained glucose $20 \mathrm{~g} / \mathrm{L}$, bacteriological peptone $10 \mathrm{~g} / \mathrm{L}$, meat extract $8 \mathrm{~g} / \mathrm{L}$, yeast extract $4 \mathrm{~g} / \mathrm{L}$, $\mathrm{CH}_{3} \mathrm{COONa} \cdot 3 \mathrm{H}_{2} \mathrm{O} 5 \mathrm{~g} / \mathrm{L}, \mathrm{K}_{2} \mathrm{HPO}_{4} 2 \mathrm{~g} / \mathrm{L}$, ammonium citrate tribasic $2 \mathrm{~g} / \mathrm{L}, \mathrm{MgSO}_{4} \cdot 7 \mathrm{H}_{2} \mathrm{O}$ $0.2 \mathrm{~g} / \mathrm{L}, \mathrm{MnSO}_{4} \cdot 4 \mathrm{H}_{2} \mathrm{O} 0.05 \mathrm{~g} / \mathrm{L}$ [33]. The working cell bank has been stored at $4{ }^{\circ} \mathrm{C}$ in MRS-agar slants for six months and used for seed cultures. The optimal growth conditions were set up in a SKI 4 incubator (ARGO LAB, Modena, Italy) for $24 \mathrm{~h}$, at $\mathrm{pH} 7.0,30^{\circ} \mathrm{C}$ under gentle stirring $(130 \mathrm{rpm})$ in Erlenmeyer flasks under microaerophilic conditions maintained by the presence of a head-space of the flasks.

\subsection{Food Waste}

Five batches of waste were collected from local agri-food industries: pear processing residues (PPR) (a mixture of unripe, overripe or damaged pears not suitable for market), tomato pomace (TP) (peels and seeds), potato pomace (PP) (damaged or broken tubers and peels), riches in carbohydrates [34], milk whey (MW), and ricotta cheese whey (RCW), which are the main by-products in cheese production processes, rich in proteins [35].

Waste were manually homogenized, divided into $250 \mathrm{~g}$ aliquots and stored at $-20{ }^{\circ} \mathrm{C}$ until further usage or analysis. Before the fermentation, they were submitted to different pre-treatments, depending on their physical characteristics, as shown in Table 1.

Table 1. Pretreatments on waste biomass before fermentation.

\begin{tabular}{ll}
\hline Biomass & Pretreatments \\
\hline Pear processing residues (PPR) & Grinding \\
Tomato pomace (TP) & Grinding and hydrolysis \\
Potato pomace (PP) & Grinding and hydrolysis \\
Milk whey (MW) & None \\
Ricotta cheese whey (RCW) & None \\
\hline
\end{tabular}


Pear-processing residues, potato and tomato pomace were grinded using a professional laboratory blender (KLARSTEIN, Berlin, Germany). Potato and tomato pomace were then submitted to hydrolysis treatment. PT and PP cannot be processed by fermentation without a preliminary hydrolysis pretreatment to obtain fermentable monomers (glucose and galacturonic acid, respectively). Hydrolysis was performed by treating $100 \mathrm{~g}$ of the waste with $250 \mathrm{~mL}$ of $1 \mathrm{M} \mathrm{HCl}$ at a temperature of about $80^{\circ} \mathrm{C}$ for $1 \mathrm{~h}$ in a $500 \mathrm{~mL}$ flask equipped with a condenser. All biomasses were sterilized in an autoclave before being fermented, and the $\mathrm{pH}$ adjusted to 7 with $0.15 \mathrm{M} \mathrm{NaOH}$.

\subsection{Inoculum of Lactobacillus Casei}

A loopful of L. casei was inoculated in $50 \mathrm{~mL}$ Erlenmeyer flasks containing $10 \mathrm{~mL}$ of sterile MRS medium and placed in an incubator at $130 \mathrm{rpm}, 30{ }^{\circ} \mathrm{C}$ for $24 \mathrm{~h}$. In the case of small-scale tests $(100 \mathrm{~mL})$, the suspension obtained is entirely used as an inoculum, while for the tests in the fermenter $(700 \mathrm{~mL})$, the suspension is used as a pre-inoculum for $70 \mathrm{~mL}$ of fresh MRS medium, which, grown under the same conditions, it is used as an inoculum.

\subsection{Small-Scale Tests (Working Volume, $100 \mathrm{~mL}$ )}

Fermentations were performed using $100 \mathrm{~mL}$ of waste in $250 \mathrm{~mL}$ flasks and inoculated with $10 \mathrm{~mL}$ of inoculum, prepared as previously described. The flasks were then placed in an incubator at $30^{\circ} \mathrm{C}, \mathrm{pH} 7$ and $130 \mathrm{rpm}$. Samples were withdrawal $(1 \mathrm{~mL})$ under sterile conditions at the beginning of the fermentation $\left(\mathrm{T}_{0}\right)$ and at the end of the process, after $72 \mathrm{~h}\left(\mathrm{~T}_{72}\right)$. Each sample was centrifuged and the supernatant analyzed to quantify carbohydrates depletion and lactic acid production, comparing with blank samples. Blank samples derived from biomasses without inoculum and submitted to the same fermentation conditions. Fermentations have been carried out with single biomasses and in mixture, as reported in Table 2.

Table 2. Substrates used for fermentation, as single biomasses or mixtures of waste.

\begin{tabular}{|c|c|c|c|c|c|}
\hline \multirow[b]{2}{*}{ Substrates for Fermentation Process } & \multicolumn{5}{|c|}{ Waste } \\
\hline & $\begin{array}{c}\text { MW } \\
(\%)\end{array}$ & $\begin{array}{c}\text { RCW } \\
(\%)\end{array}$ & $\begin{array}{c}\text { PPR } \\
(\%)\end{array}$ & $\begin{array}{l}\text { PP } \\
\text { (\%) }\end{array}$ & $\begin{array}{l}\text { TP } \\
(\%)\end{array}$ \\
\hline MW & 100 & & & & \\
\hline RCW & & 100 & & & \\
\hline PPR pretreated & & & 100 & & \\
\hline PP pretreated & & & & 100 & \\
\hline $\mathrm{TP}$ pretreated & & & & & 100 \\
\hline PP pretreated + TP pretreated & & & & 50 & 50 \\
\hline MW + PPR pretreated & 50 & & 50 & & \\
\hline MW + PPR pretreated & 30 & & 70 & & \\
\hline MW + PPR pretreated & 70 & & 30 & & \\
\hline $\mathrm{RCW}+\mathrm{PPR}$ pretreated & & 50 & 50 & & \\
\hline RCW + PPR pretreated & & 30 & 70 & & \\
\hline $\mathrm{RCW}+\mathrm{PPR}$ pretreated & & 70 & 30 & & \\
\hline $\mathrm{RCW}+\mathrm{PP}$ pretreated & & 50 & & 50 & \\
\hline $\mathrm{RCW}+\mathrm{PP}$ pretreated $+\mathrm{TP}$ pretreated & & 60 & & 20 & 20 \\
\hline
\end{tabular}

\subsection{L-Scale Batch Fermentation (Working Volume, $700 \mathrm{~mL}$ )}

Batch fermentations were carried out in a thermoregulated autoclavable Minifors ${ }^{\mathrm{TM}}$ bioreactor (INFORS, Basel, Switzerland) of $700 \mathrm{~mL}$ of working volume (1 L of overall capacity), equipped with probes for $\mathrm{pH}$, temperature and $\mathrm{O}_{2}$ concentration monitoring (METTLER TOLEDO, Columbus, OH, USA). $\mathrm{pH}$ value was automatically maintained at 7.0 by adding $1 \mathrm{~N} \mathrm{NaOH}$ solution. The inoculum in MRS medium $(70 \mathrm{~mL}, 10 \% v / v)$ was incubated at $130 \mathrm{rpm}$ for $24 \mathrm{~h}$ on a shaking thermostatic incubator before the addition to the fermenter. Temperature and $\mathrm{pH}$ of inoculum were initially set up at $30^{\circ} \mathrm{C}$ or $37^{\circ} \mathrm{C}$ and $\mathrm{pH}$ 7.0. Before inoculation, the fermenter was filled with the pretreated waste biomasses. 
The culture was maintained at $50 \mathrm{rpm}$ by a mechanical stirrer. An airflow of $0.5 \mathrm{~L} / \mathrm{min}$ was fluxed on the head space of the fermenter, as needed to maintain a slight overpressure. Before each fermentation, the fermenter was sanitized under steam stripping conditions $\left(100{ }^{\circ} \mathrm{C}\right.$ for $\left.30 \mathrm{~min}\right)$. Batch processes were followed for a maximum of $144 \mathrm{~h}$, samples collected after the first $6 \mathrm{~h}$ and then every $24 \mathrm{~h}$. All experiments and analyses were repeated in triplicate and averaged.

\subsection{Analytical Methods}

Moisture has been determined using the thermogravimetric method [36], protein using the Kieldhal method [37] and ash content by means of the gravimetric assays [38]. Total sugars content has been determined by means of the phenol-sulfuric acid method [39], that is the most reliable method among all the quantitative assays for total carbohydrates estimation. In hot acidic medium, glucose is dehydrated to hydroxymethyl furfural. This forms a yellow-brown-colored product with phenol and has absorption maximum at 490 nm VIS spectroscopy.

Sugars (glucose, fructose, galactose, lactose) and sorbitol were analyzed by HPLC (Jasco, Easton, MD, USA) equipped with a refractive index detector (Jasco, Oklahoma City, OK, USA) and UV detector (Jasco, Oklahoma City, OK, USA) and Rezex ROA-Organic Acid $\mathrm{H}+(8 \%), 300 \times 7.8 \mathrm{~mm}$ (Phenomenex, Torrance, CA, USA).

Isocratic elution was carried out at $60{ }^{\circ} \mathrm{C}$ with $0.6 \mathrm{~mL} / \mathrm{min}$ of $0.01 \mathrm{M} \mathrm{H}_{2} \mathrm{SO}_{4}$. Before the HPLC analysis, samples were centrifuged (6720 RCF; $10 \mathrm{~min})$, placed at $80{ }^{\circ} \mathrm{C}$ for $10 \mathrm{~min}$ to eliminate possible interferences due to microbial enzymes and filtered using cellulose acetate filters (porosity $0.2 \mu \mathrm{m}$ ).

Yield of LA per gram of sugars $\left(\mathrm{Y}_{\mathrm{LA}}\right)$ was calculated by dividing the LA concentration by the total fermentable carbohydrates concentrations present in the starting material. Yield of LA per gram of food waste $\left(\mathrm{Y}_{\mathrm{FW}}\right)$ was calculated by dividing LA present in the reactor by dry matter of the respective waste. Since LA formation is growth-associated, productivity of batch cultures was calculated with LA titer after $8 \mathrm{~h}$.

\section{Results}

\subsection{Small-Scale Fermentations of L. casei (Working Volume, $100 \mathrm{~mL}$ )}

The chemical composition of the residues is reported in Table 3. Biomasses characterization is referred to their effective composition just before being fermented, in order to consider the effect of possible material losses during pretreatments and organic molecules degradation (especially sugars and N-based molecules) during autoclaving caused by the well-known Maillard reaction.

Table 3. Chemical composition of the residues and waste used in this study.

\begin{tabular}{lccccc}
\hline & PPR & RCW & MW & TP & PP \\
\hline Moisture (\% w/v) & $11.4 \pm 0.7$ & $93.9 \pm 0.8$ & $94.0 \pm 1.2$ & $15.1 \pm 1.3$ & $71.1 \pm 0.9$ \\
Total carbohydrates (TC)(g/L) & $80.3 \pm 2.3$ & $85.3 \pm 2.2$ & $51.4 \pm 1.0$ & $33.3 \pm 0.5$ & $68.7 \pm 1.3$ \\
Protein (N 6.25) (g/L) & 3.1 & 6.1 & 8.0 & 19.3 & 8.0 \\
Ash (g/L) & $9.0 \pm 0.7$ & $1.2 \pm 0.0$ & $7.0 \pm 0.6$ & $3.9 \pm 0.2$ & $6.3 \pm 0.4$ \\
\hline
\end{tabular}

Any organic acids, including LA, have been measured at detectable level in samples. Total carbohydrates (TC) comprise different type of sugars, which typically characterized the agri-food residues.

The homo fermentative L(+)-enantiomer producing bacterium L. casei DSM 20011 (ATCC 393) has been used for LA production. In general, homo fermentative organisms have the conversion efficiency of 1 mol glucose to 2 mol LA [40].

In order to evaluate the capacity of L. casei to grow and produce LA on the agri-food used in this study, preliminary tests have been carried out on single substrate. Then, small-scale fermentations have been set up, mixing different residues. In particular, highmoisture waste as MW and RCW have been added to the others pretreated wastes. In 
the case of PPR only grinding and homogenization were necessary, because it contains readily fermentable sugars, as fructose. In this study, $\mathrm{HCl}$-hydrolysis has been carried out, even though in the case of industrial application the use of enzymes has been strongly recommended [41]. Table 4 shows the total sugar concentrations present in the different matrices, the respective concentration of lactic acid obtained after $72 \mathrm{~h}$ of fermentation with L. casei and the consequent percentage yield factor $\mathrm{Y}_{\mathrm{LA}}$.

Table 4. Small-scale lactic acid fermentations (100 mL).

\begin{tabular}{|c|c|c|c|c|}
\hline Waste & Ratio & Total Fermentable Carbohydrates (g/L) & Lactic Acid (g/L) & $\begin{array}{l}Y_{\text {LA }} \\
(\%)\end{array}$ \\
\hline MW & 100 & $51.4 \pm 1.0$ & $15.3 \pm 0.9$ & $30.4 \pm 1.7 \%$ \\
\hline $\mathrm{RCW}$ & 100 & $85.3 \pm 2.2$ & $34.0 \pm 0.3$ & $40 \pm 2.2 \%$ \\
\hline PPR pretreated & 100 & $80.3 \pm 2.3$ & $29.6 \pm 2.3$ & $36.8 \pm 2.5 \%$ \\
\hline TP pretreated & 100 & $33.3 \pm 0.5$ & $8.91 \pm 0.2$ & $27.0 \pm 0.3 \%$ \\
\hline PP pretreated & 100 & $68.7 \pm 1.3$ & $20.2 \pm 1.5$ & $30.6 \pm 2.1 \%$ \\
\hline MW + PPR pretreated & $50: 50$ & $65.8 \pm 3.3$ & $28.6 \pm 1.5$ & $44.0 \pm 1.3 \%$ \\
\hline MW + PPR pretreated & $30: 70$ & $71.7 \pm 2.7$ & $25.6 \pm 0.6$ & $36 \pm 3.2 \%$ \\
\hline MW + PPR pretreated & $70: 30$ & $59.7 \pm 1.4$ & $24.8 \pm 2.2$ & $41.5 \pm 1.6 \%$ \\
\hline RCW + PPR pretreated & $50: 50$ & $82.4 \pm 1.4$ & $29.9 \pm 0.6$ & $35.4 \pm 0.8 \%$ \\
\hline $\mathrm{RCW}+\mathrm{PPR}$ pretreated & $30: 70$ & $81.5 \pm 2.3$ & $25.4 \pm 1.9$ & $31,2 \pm 1.4 \%$ \\
\hline RCW + PPR pretreated & $70: 30$ & $84.3 \pm 1.6$ & $38.8 \pm 0.4$ & $46.0 \pm 0.7 \%$ \\
\hline $\mathrm{RCW}+\mathrm{PP}$ & $50: 50$ & $59.4 \pm 1.7$ & $24.6 \pm 0.6$ & $41.4 \pm 1.8 \%$ \\
\hline $\mathrm{RCW}+\mathrm{PP}+\mathrm{TP}$ & $60: 20: 20$ & $71.6 \pm 0.5$ & $21.5 \pm 1.3$ & $29.8 \pm 0.7 \%$ \\
\hline
\end{tabular}

As it can be seen, the yields were generally low, due to the fact that in small-scale tests $\mathrm{pH}$ cannot be regulated and spontaneously tends to reach acidic values jeopardizing the biomass growth. In fact, the aim of these tests principally was to exclude the presence of toxic substances that could have been inhibited microbial growth.

Small-scale preliminary trials have shown that the potential as a substrate for lactic fermentation is promising. The different mixing percentages of MW / RCW and PPR also had the purpose of evaluating the "workability" of the final fermentation medium. As the percentage of $\mathrm{MW} / \mathrm{RCW}$ increased, the medium appeared less dense and the fibrous parts of the plant matrix more diluted. With the same yield obtained, the mixture containing RCW and pear (70:30) was considered the best result for the following experiments. Mixtures between RCW and PP, and RCW, PP, and PT have shown that even the addition of these matrices generates a medium that may be suitable for the production of lactic acid.

\subsection{L-Scale Batch Fermentation}

Based on the results obtained from the small-scale tests, a scaling-up to $1 \mathrm{~L}$ has been carried out, in order to control the operating conditions such as $\mathrm{pH}$ and oxygen concentration that could not be monitored in small-scale tests and improve the yields. In these tests, the consumption of the various carbon sources has been monitored, together with the production of LA at different time scales. As mentioned above, the most promising waste mixtures was $\mathrm{RCW}+\mathrm{PPR}$ at a ratio of 70:30. As a comparison, an in order to understand the separate contribution of the two matrices, a fermentation with the sole RCW has been carried out.

\subsubsection{L-Scale Batch Fermentations with RCW at Different Temperatures}

In the literature, examples of lactic acid production using continuous [28] and fedbatch [42] fermentations are reported but the batch system is still the simplest system that guarantees high fermentation yields. For improving the yield in LA, batch fermentations have been set up at two different temperatures, $30^{\circ} \mathrm{C}$ and $37^{\circ} \mathrm{C}$, respectively. Based on HPLC results on RCW, about $96 \%$ of the total carbohydrates in RCW is represented by lactose $(82.4 \pm 1.4 \mathrm{~g} / \mathrm{L}), 3.5 \%$ by galactose $(3.0 \pm 0.3 \mathrm{~g} / \mathrm{L})$ and about $0.5 \%$ of glucose $(0.4 \pm 0.0 \mathrm{~g} / \mathrm{L})$. 
In Figure 1 the results deriving from the fermentation of $\mathrm{RCW}$ at $30^{\circ} \mathrm{C}$ and $37^{\circ} \mathrm{C}$ are reported.

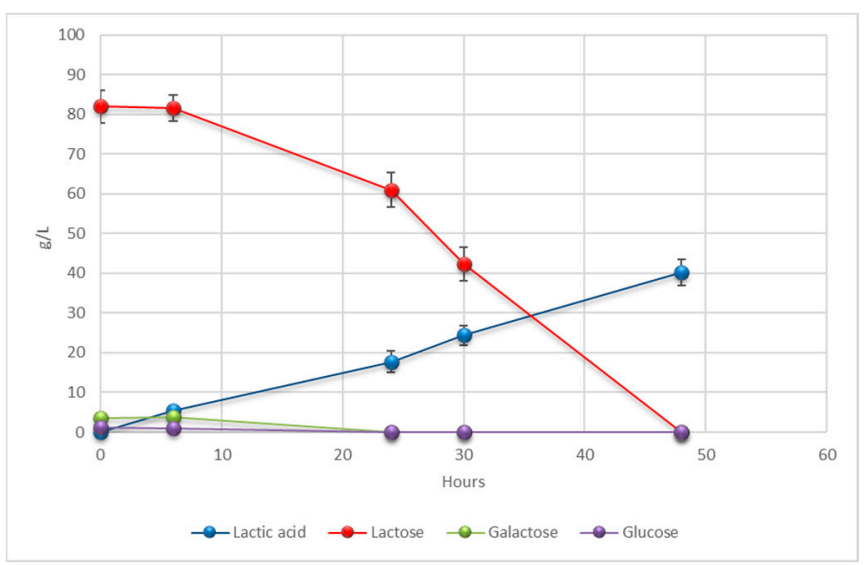

(a)

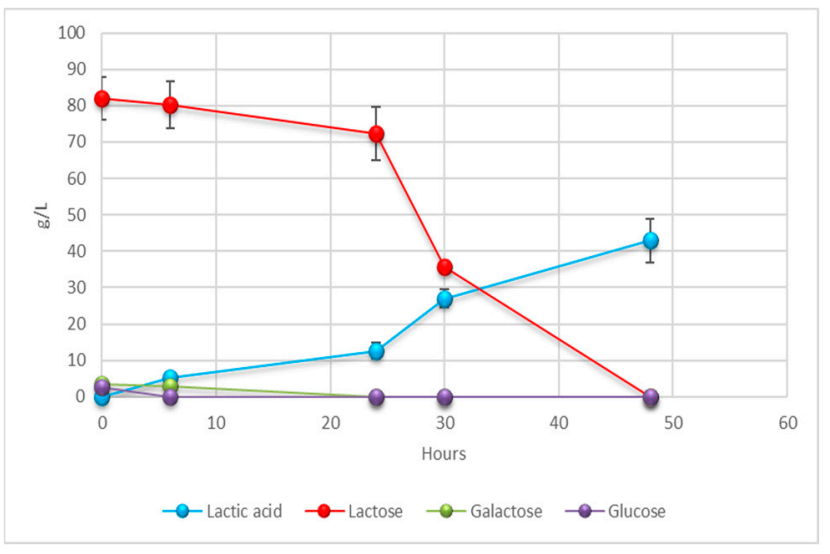

(b)

Figure 1. Trend in the concentration of sugars and LA in fermentations with RCW: (a) $30^{\circ} \mathrm{C}$; (b) $37^{\circ} \mathrm{C}$.

The fermentations were carried out in both cases for $48 \mathrm{~h}$ until the complete consumption of the available sugars. Regarding LA production, $40.2 \mathrm{~g} / \mathrm{L}$ were obtained in fermentations carried out at $30{ }^{\circ} \mathrm{C}$ with a yield $\mathrm{Y}_{\mathrm{LA}}=47.3 \%$ on total sugars and a volumetric productivity $\mathrm{Q}_{\mathrm{p}}=0.98 \mathrm{~g} / \mathrm{L} \cdot \mathrm{h}$. In the case of fermentations carried out at $37{ }^{\circ} \mathrm{C}$, an amount of LA equal to $43 \mathrm{~g} / \mathrm{L}$ was obtained, corresponding to a fermentation yield $\mathrm{Y}_{\mathrm{LA}}=50.6 \%$ on total sugars and a volumetric productivity $\mathrm{Q}_{\mathrm{p}}=1.05 \mathrm{~g} / \mathrm{L} \cdot \mathrm{h}$.

Both graphs show the depletion of lactose, galactose and glucose over $48 \mathrm{~h}$ as the concentration of LA increases. As expected, LA is production is mostly attributable to the consumption of lactose, but L. casei uses also glucose and galactose as carbon source [43]. The effect of temperature seems to be the occurring of a prolonged lag phase at $30^{\circ} \mathrm{C}$. At $37^{\circ} \mathrm{C}$, lactose concentration does not decrease significantly until the complete depletion of glucose and galactose. The higher yield of LA at $37^{\circ} \mathrm{C}$ is coherent with results previously obtained [44] at the same $\mathrm{pH}$ value and with an inoculum age of $24 \mathrm{~h}$, as in our study. Nevertheless, considering the very slight difference in both yield and productivity between the two temperatures tested, we decided to use $30^{\circ} \mathrm{C}$ as reference temperature because of the advantages in terms of process costs to maintain higher temperature. In fact, $30{ }^{\circ} \mathrm{C}$ can be considered as room temperature in summer in Italy and any equipment has to be provided to heat the fermenter.

\subsubsection{L-Scale Batch Fermentations with RCW + PPT}

These fermentations were carried out in order to scale up the most promising matrix in the production of lactic acid from the small-scale trials. The RCW + PPR pretreated (ratio 70:30) has shown a fermentation yield of about $46 \%$ in small-scale tests.

Scaling up to the fermenter scale, different kind of pretreatments have been investigated, in order to reduce as much as possible, the process costs, as mentioned above. In particular, a comparison between grinded PPT and grinded and the supernatant of grinded and centrifuged PPR has been attempt. The supernatant would contain soluble sugars and nutrients, and by removing the fibrous part, the culture medium appears less dense and viscous. The results of this test may also be important for the purpose of recovering LA from the fermentation broth and for the setup of the downstream protocol. Considering the fact that centrifugation reduces the mass by approximately $50 \%$, the amount of PPR has been appropriately increased to $90: 10$, in order to maintain the same total sugars content of the two batches. Table 5 shows the sugar concentrations of the respective starting mixtures with RCW + PPR in both cases. It is worthwhile noting that, even if the total sugars concentrations are almost identically in the two cases, the sugars speciation is different, due 
to the more percentage of RCW in the 90:10 ratio fermentation, which enriches the medium of lactose. Fructose and galactose have been reported as a sum because in the HPLC elution conditions this two isomers cannot be differentiated, having the same retention time. Sorbitol, as well as fructose, derived from PPR, being both among the principal components of soluble organic matter of pears.

Table 5. Sugar composition of the mixtures of RCW + PPR (70:30) and RCW + centrifuged PPR (90:10).

\begin{tabular}{lccccc}
\hline & $\begin{array}{c}\text { Total Sugars } \\
(\mathbf{g} / \mathbf{L})\end{array}$ & $\begin{array}{c}\text { Lactose } \\
(\mathrm{g} / \mathrm{L})\end{array}$ & $\begin{array}{c}\text { Fructose/Galactose } \\
(\mathrm{g} / \mathrm{L})\end{array}$ & $\begin{array}{c}\text { Glucose } \\
(\mathrm{g} / \mathrm{L})\end{array}$ & $\begin{array}{c}\text { Sorbitol } \\
(\mathrm{g} / \mathrm{L})\end{array}$ \\
\hline RCW + PPR (70:30) & $84.0 \pm 4.2$ & $57.0 \pm 2.5$ & $12.2 \pm 2.1$ & $6.2 \pm 0.3$ & $8.0 \pm 1.2$ \\
RCW + centrifuged PPR (90:10) & $84.5 \pm 5.9$ & $74.0 \pm 3.5$ & $4.7 \pm 0.6$ & $4.6 \pm 1.4$ & $3.9 \pm 0.2$ \\
\hline
\end{tabular}

In Figure 2 is shown the trends of batch fermentations carried out with RCW + PPR (70:30) and RCW + centrifuged PPR (90:10), respectively.

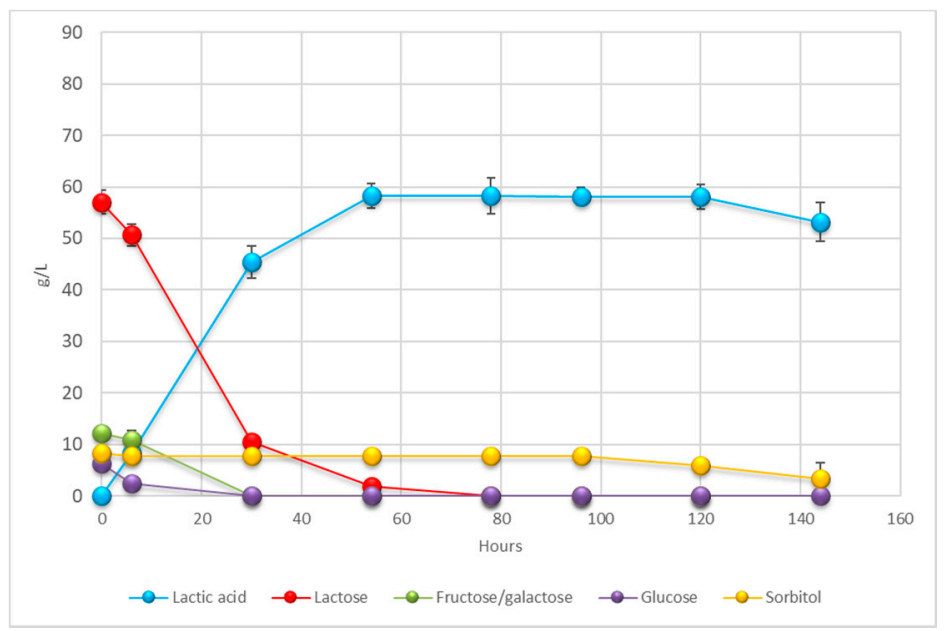

(a)

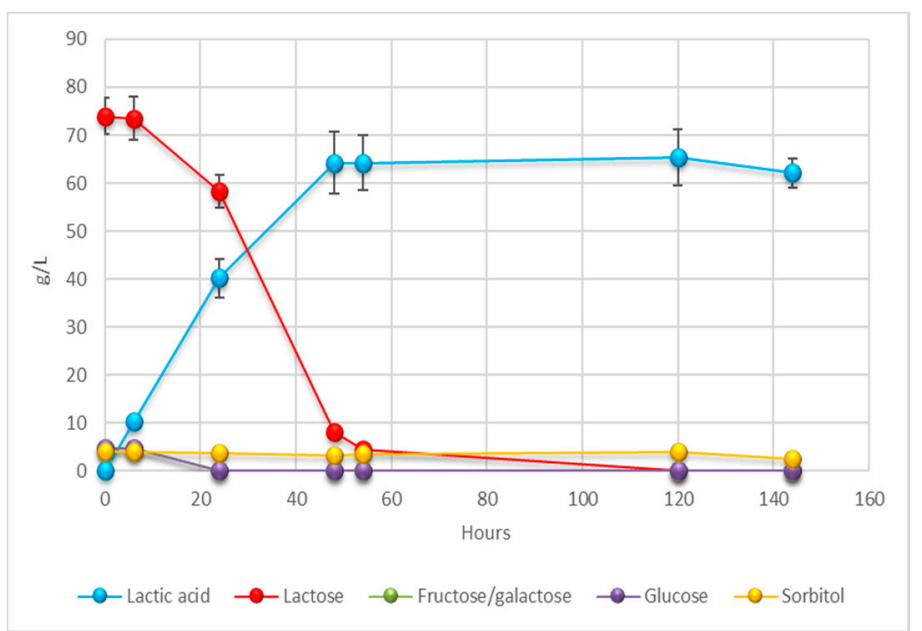

(b) 1

Figure 2. Trends in the concentration of sugars and LA in fermentations with RCW + PPR (70:30) (a) and RCW + centrifuged PPR (90:10) (b), respectively. ${ }^{\mathbf{1}}$ the trend of fructose and galactose is covered by that of glucose.

In the RCW + PPR (70:30) batch fermentation, L. casei quickly begins to metabolize the available sugars, with a very short lag phase and in less than $60 \mathrm{~h}$ all sugars have been completely depleted, with a production of $59.2 \mathrm{~g} / \mathrm{L}$ of LA. Otherwise, in the RCW + PPR 
(90:10) batch fermentation the trend in sugars depletion is almost identical, except for a shot lag phase in the first $8 \mathrm{~h}$. In the first $24 \mathrm{~h}$, fructose, galactose, and glucose were completely metabolized and lactose significantly decreased. In the RCW + PPR (90:10) batch fermentation at $58 \mathrm{~h}$ there is the maximum production of $65.4 \mathrm{~g} / \mathrm{L}$ of LA.

In both fermentations, sorbitol has maintained its concentration constant at the initial values during all the processes, with a slight decrease at the very end of the process, toghether with a decrease in LA concentration, probably due to the fact that, in absence of other carbon sources and with the depletion of other nutrients, L. casei has started to consume the residual carbon sources present. The ability of L. casei to utilize D-sorbitol as carbon source has been already reported [45]. After about $60 \mathrm{~h}$ of fermentation, the yields were $\mathrm{Y}_{\mathrm{LA}} 77.2 \%$ and $\mathrm{Y}_{\mathrm{LA}}$ 78.3\% for RCW + PPR (70:30) and RCW + PPR (90:10), respectively.

As a result, the removal of the fibrous part of PPR does not seem to provide significant differences in the production yield. The greatest amount as absolute value of LA $(65.4 \mathrm{~g} / \mathrm{L})$ derives from the greatest amount of fermentable sugars in the starting mixture $(84.5 \mathrm{~g} / \mathrm{L})$. Moreover, being similar the process duration until the complete sugars depletion, the volumetric productivity is similar $\left(Q_{p}=1.05 \mathrm{~g} / \mathrm{L} \cdot \mathrm{h}\right.$ and $\mathrm{Q}_{\mathrm{p}}=1.12 \mathrm{~g} / \mathrm{L} \cdot \mathrm{h}$, respectively).

As a second important results, it seems that the addition of a centrifugation step in the upstream does not have significant effects on the fermentation. Taking into account the industrial costs deriving from the insertion of a centrifugation step upstream of fermentation, it is not believed that this entails an advantage in terms of production.

\section{Discussion}

In this study, the capacity to be fermented by various waste biomass has been studied starting from small-scale tests, in order to evaluate the possible presence of toxic substances for L.casei during LA production, the general conditions of growth and the potential yield of LA production. Based on the analyses carried out and the results obtained, it could be evidenced the promising potential of the some agri-food waste, used as single or mixed sources. As reported in literature, for PPR, the prompt fermentable fructose represents more than $75 \%$ of the TC [32], whereas TP is constituted for about $22 \%$ by pectin (as galacturonic acid) [38] and PP of about 75\% by starch [5]. In RCW and MW TC fraction is made up by the sole lactose [39]. The approach that involves the use of mixed waste biomass essentially derives from the need to set up an operational plan that overcomes the problem of the seasonal nature of waste and makes it possible to set up a production system that works throughout the year. In fact, RCW and MW do not derive from food-chain directly connected to agricultural production and are always available, unlike fruit and vegetable waste which have rather short periods of quantitative peaks, are then no longer available in all other months of the year and it is inconceivable to refrigerate and storage them for a long time.

Small-scale trials have shown that the LA production is promising, and that, as already highlighted, the agri-food waste considered in this study are suitable for fermentation by L. casei to obtain LA. In fact, they do not contain toxic substances for the growth and development of the microorganism, they contain a sufficient quantity of other nutrients (organic and inorganic nitrogen, mineral salts) to support microbial growth without adding any other nutrients, and do not require particular pre-treatments before fermentation.

Moreover, the yields in LA obtained in mixed fermentations were averagely similar or higher than yields of the single-substrates, confirming that L. casei is able to grow on different carbon sources. This is particularly important in view of the future perspective of a continuous fermentation processes where different residues and waste could be progressively integrated from time to time depending of the seasonal availability to a "base ground" of MW and RCW, making it possible to setup a production system that works throughout the year or at least during the entire agricultural season.

Preliminary tests carried out on $1 \mathrm{~L}$ scale fermenter have been realized with RCW rather than MW because at local level RCW is the very final waste of the dairy production supply chain, whereas MW could be currently used for ricotta cheese production and 
it is not always available on market. Then, PPT was the first agri-food waste because it has presented the best performance at small scale, but it is only the first step in order to optimize the continuous process, as above mentioned.

Preliminary tests carried on batch fermentations (1 L-scale) have permitted to almost doubled the LA yield, controlling the fermentation parameters as $\mathrm{pH}$, temperature and level of oxygen. The have been carried out on RCW in order to understand the fermentation potential of the base-medium. The purpose of the test was to verify whether the increase in temperature could have an effect on the speed of sugar consumption and on the production of lactic acid, decreasing fermentation times. Based on the results obtained, we concluded that there are no substantial differences either in terms of product yield or in process speed, between $30^{\circ} \mathrm{C}$ and $37^{\circ} \mathrm{C}$. On the contrary, as the temperature increases, the management costs of the process would increase, having to use thermal energy to heat the fermenter. The increase in temperature was therefore not interesting for the purposes of the project.

PPR was used as a model biomass, together with RCW, testing the fermentation of the biomass as it is, only homogenized, and of the biomass previously centrifuged to remove the fibrous part. From the results obtained it emerged that the removal of the fibrous part of the pear was not decisive, as it did not give significant differences in the production yield if compared to the test in which the fibrous component is present. Taking into account the industrial costs deriving from the insertion of a centrifugation step upstream of fermentation, it is not believed that this entails an advantage in terms of production.

Overall, the LA yield obtained in fermenter, even if doubled with respect to small-scale tests, are still rather lower in comparison to the theoretical yield, but comparable to those obtained in other studies where LA is produced by different kind of waste biomass, as a yield of $52,4 \%$ reported by Ge et al. [46] from Jerusalem artichoke residues, or $81.4 \%$ from tamarind kernel [47] and 70\% fermenting hydrolyzed corn stover [48]. In all those cases, and in the present research, the key aspect should not be the yield optimization but the possibility to valorize a waste and recovery a value-added product at the lowest costs as possible.

\section{Conclusions}

In conclusion, all the tests carried out have shown that the most satisfactory fermentations are certainly those carried out with the RCW matrix, individually and in the form of a mixture with pear pulp waste. RCW as such is a waste from the agro-industrial dairy industry, it is available all year round and having no supply problems linked to seasonality, it could be used as a fermentation base to be added to other agro-industrial waste present only in certain seasons. Furthermore, RCW does not currently have a defined position in terms of reuse, as whey does in the feed sector. In the future, its potential use as a fermentation substrate would allow a real enhancement as a by-product. It could then regain a second life and be reintroduced to the market for the production of LA. Further investigations will be necessary, integrating in the fermenter the other biomass and testing the best fermentation strategy which optimize the overall fermentation performance in terms of yield and productivity without burdening on process costs.

Author Contributions: Conceptualization and methodology: S.C. and E.T.; formal analysis: I.R. and B.S.; investigation: D.S. and F.Z.; writing-original draft preparation: S.C.; writing-review and editing: S.C., E.T.; supervision: E.T.; All authors have read and agreed to the published version of the manuscript.

Funding: This research received no external funding.

Institutional Review Board Statement: Not applicable.

Informed Consent Statement: Not applicable.

Acknowledgments: The authors would like to acknowledge Federica Fruscella for technical support.

Conflicts of Interest: The authors declare no conflict of interest. 


\section{References}

1. Arshadi, M.; Attard, T.M.; Lukasik, R.M.; Brncic, M.; Lopes, A.M.D.C.; Finell, M.; Geladi, P.; Gerschenson, L.N.; Gogus, F.; Herrero, M.; et al. Pre-treatment and extraction techniques for recovery of added value compounds from wastes throughout the agri-food chain. Green Chem. 2016, 18, 6160-6204. [CrossRef]

2. The Extent of Food Waste Generation across EU-27: Different Calculation Methods and the Reliability of Their Results-KlausRainer Bräutigam, Juliane Jörissen, Carmen Priefer. 2014. Available online: https://journals.sagepub.com/doi/full/10.1177/07 $34242 \$$ times $\$ 14545374$ (accessed on 2 November 2020).

3. Caldeira, C.; De Laurentiis, V.; Corrado, S.; Van Holsteijn, F.; Sala, S. Quantification of food waste per product group along the food supply chain in the European Union: A mass flow analysis. Resour. Conserv. Recycl. 2019, 149, 479-488. [CrossRef] [PubMed]

4. Šmplák, R.; Kůdela, J.; Smejkalová, V.; Nevrlý, V.; Pavlas, M.; Hrabec, D. Pricing and advertising strategies in conceptual waste management planning. J. Clean. Prod. 2019, 239, 118068. [CrossRef]

5. $\quad$ Fritsch, C.; Staebler, A.; Happel, A.; Márquez, M.A.C.; Aguiló-Aguayo, I.; Abadias, M.; Gallur, M.; Cigognini, I.M.; Montanari, A.; López, M.; et al. Processing, valorization and application of bio-waste derived compounds from potato, tomato, olive and cereals: A review. Sustainability 2017, 9, 1492. [CrossRef]

6. Mirabella, N.; Castellani, V.; Sala, S. Current options for the valorization of food manufacturing waste: A review. J. Clean. Prod. 2014, 65, 28-41. [CrossRef]

7. Muscio, A.; Sisto, R. Are agri-food systems really switching to a circular economy model? Implications for European research and innovation policy. Sustainability 2020, 12, 5554. [CrossRef]

8. Gontard, N.; Sonesson, U.; Birkved, M.; Majone, M.; Pavan, P.; Celli, A.; Angellier-Coussy, H.; Jang, G.-W.; Verniquet, A.; Broeze, J.; et al. A research challenge vision regarding management of agricultural waste in a circular bio-based economy. Crit. Rev. Environ. Sci. Technol. 2018, 48, 614-654. [CrossRef]

9. Cubas-Cano, E.; González-Fernández, C.; Ballesteros, M.; Tomás-Pejó, E. Biotechnological advances in lactic acid production by lactic acid bacteria: Lignocellulose as novel substrate. Biofuels Bioprod. Biorefining 2018, 12, 290-303. [CrossRef]

10. Dusselier, M.; Van Wouwe, P.; Dewaele, A.; Makshina, E.V.; Sels, B.F. Lactic acid as a platform chemical in the biobased economy: The role of chemocatalysis. Energy Environ. Sci. 2013, 6, 1415-1442. [CrossRef]

11. Srivastava, A.; Narayanan, N.; Roychoudhury, P.K. L (+) lactic acid fermentation and its product polymerization. Electron. J. Biotechnol. 2004, 7, 167-178. [CrossRef]

12. Kim, M.-S.; Na, J.-G.; Lee, M.-K.; Ryu, H.; Chang, Y.K.; Triolo, J.M.; Yun, Y.-M.; Kim, D.-H. More value from food waste: Lactic acid and biogas recovery. Water Res. 2016, 96, 208-216. [CrossRef] [PubMed]

13. Djukic-Vukovic, A.; MladenoviĆ, D.; Ivanović, J.; Pejin, J.; Mojović, L. Towards sustainability of lactic acid and poly-lactic acid polymers production. Renew. Sustain. Energy Rev. 2019, 108, 238-252. [CrossRef]

14. Zhang, X.; Lin, L.; Zhang, T.; Liu, H.; Zhang, X. Catalytic dehydration of lactic acid to acrylic acid over modified ZSM-5 catalysts. Chem. Eng. J. 2016, 284, 934-941. [CrossRef]

15. Alsaheb, R.A.A.; Aladdin, A.; Othman, N.Z.; Malek, R.A.; Leng, O.M.; Aziz, R.; El Enshasy, H.A. Lactic acid applications in pharmaceutical and cosmeceutical industries. J. Chem. Pharm. Res. 2015, 7, 729-735.

16. Wee, Y.-J.; Kim, J.-N.; Ryu, H.-W. Biotechnological production of lactic acid and its recent Ap-plications. Food Technol. Biotechnol. 2006, 44, 163-172.

17. Leroy, F.; De Vuyst, L. Lactic acid bacteria as functional starter cultures for the food fermentation industry. Trends Food Sci. Technol. 2004, 15, 67-78. [CrossRef]

18. Girotto, F.; Alibardi, L.; Cossu, R. Food waste generation and industrial uses: A review. Waste Manag. 2015, 45, 32-41. [CrossRef]

19. Eş, I.; Khaneghah, A.M.; Barba, F.J.; Saraiva, J.A.; Sant'Ana, A.S.; Hashemi, S.M.B. Recent advancements in lactic acid production -A review. Food Res. Int. 2018, 107, 763-770. [CrossRef]

20. Pandey, A.; Soccol, C.R.; Nigam, P.; Soccol, V.T.; Vandenberghe, L.P.; Mohan, R. Biotechnological potential of agro-industrial residues. II: Cassava bagasse. Bioresour. Technol. 2000, 74, 81-87. [CrossRef]

21. Pandey, A.; Soccol, C.R.; Nigam, P.; Soccol, V.T. Biotechnological potential of agro-industrial residues. I: Sugarcane bagasse. Bioresour. Technol. 2000, 74, 69-80. [CrossRef]

22. Xue, M.; Liu, D.; Zhang, H.; Qi, H.; Lei, Z. A pilot process of solid state fermentation from sugar beet pulp for the production of microbial protein. J. Ferment. Bioeng. 1992, 73, 203-205. [CrossRef]

23. Antier, P.; Minjares, A.; Roussos, S.; Raimbault, M.; Viniegra-Gonzalez, G. Pectinase-hyperproducing mutants of Aspergillus niger C28B25 for solid-state fermentation of coffee pulp. Enzym. Microb. Technol. 1993, 15, 254-260. [CrossRef]

24. Gullón, B.; Yáñez, R.; Alonso, J.; Parajó, J. 1-Lactic acid production from apple pomace by sequential hydrolysis and fermentation. Bioresour. Technol. 2008, 99, 308-319. [CrossRef] [PubMed]

25. Ramachandran, S.; Singh, S.K.; Larroche, C.; Soccol, C.R.; Pandey, A. Oil cakes and their biotechnological applications-A review. Bioresour. Technol. 2007, 98, 2000-2009. [CrossRef] [PubMed]

26. Peng, X.; Chen, H. Single cell oil production in solid-state fermentation by Microsphaeropsis sp. from steam-exploded wheat straw mixed with wheat bran. Bioresour. Technol. 2008, 99, 3885-3889. [CrossRef] [PubMed]

27. Martinez, F.A.C.; Balciunas, E.M.; Salgado, J.M.; González, J.M.D.; Converti, A.; Oliveira, R.P.D.S. Lactic acid properties, applications and production: A review. Trends Food Sci. Technol. 2013, 30, 70-83. [CrossRef] 
28. Abdel-Rahman, M.A.; Tashiro, Y.; Sonomoto, K. Recent advances in lactic acid production by microbial fermentation processes. Biotechnol. Adv. 2013, 31, 877-902. [CrossRef]

29. Mazzoli, R.; Bosco, F.; Mizrahi, I.; Bayer, E.A.; Pessione, E. Towards lactic acid bacteria-based biorefineries. Biotechnol. Adv. 2014, 32, 1216-1236. [CrossRef]

30. Van De Guchte, M.; Serror, P.; Chervaux, C.; Smokvina, T.; Ehrlich, S.D.; Maguin, E. Stress responses in lactic acid bacteria. Antonie Van Leeuwenhoek 2002, 82, 187-216. [CrossRef]

31. Dedenaro, G.; Costa, S.; Rugiero, I.; Pedrini, P.; Tamburini, E. Valorization of agri-food waste via fermentation: Production of l-lactic acid as a building block for the synthesis of biopolymers. Appl. Sci. 2016, 6, 379. [CrossRef]

32. Greggio, N.; Balugani, E.; Carlini, C.; Contin, A.; Labartino, N.; Porcelli, R.; Quaranta, M.; Righi, S.; Vogli, L.; Marazza, D Theoretical and unused potential for residual biomasses in the Emilia Romagna Region (Italy) through a revised and portable framework for their categorization. Renew. Sustain. Energy Rev. 2019, 112, 590-606. [CrossRef]

33. De Man, J.C.; Rogosa, M.; Sharpe, M.E. A medium for the cultivation of lactobacilli. J. Appl. Bacteriol. 2008, 23, 130-135. [CrossRef]

34. Lui, M.Y.; Wong, C.Y.Y.; Choi, A.W.-T.; Mui, Y.F.; Qi, L.; Horváth, I.T. Valorization of carbohydrates of agricultural residues and food wastes: A key strategy for carbon conservation. ACS Sustain. Chem. Eng. 2019, 7, 17799-17807. [CrossRef]

35. Morr, C.V.; Ha, E.Y.W. Whey protein concentrates and isolates: Processing and functional properties. Crit. Rev. Food Sci. Nutr. 1993, 33, 431-476. [CrossRef] [PubMed]

36. Mauer, L.; Bradley, R.L. Moisture and Total Solids Analysis; Springer Science and Business Media LLC: Berlin, Germany, 2017; pp. 257-286.

37. Maehre, H.K.; Dalheim, L.; Edvinsen, G.K.; Elvevoll, E.O.; Jensen, I.-J. Protein determination—Method matters. Foods 2018, 7, 5. [CrossRef] [PubMed]

38. Mortensen, A.B.; Wallin, H. Gravimetric determination of ash in foods: NMKL collaborative study. J. Assoc. Off. Anal. Chem. 1989, 72, 481-483. [CrossRef] [PubMed]

39. Jain, V.M.; Karibasappa, G.N.; Dodamani, A.S.; Mali, G.V. Estimating the carbohydrate content of various forms of tobacco by phenol-sulfuric acid method. J. Educ. Health Promot. 2017, 6, 90. [CrossRef]

40. Reddy, G.; Altaf, M.D.; Naveena, B.; Venkateshwar, M.; Kumar, E.V. Amylolytic bacterial lactic acid fermentation-A review. Biotechnol. Adv. 2008, 26, 22-34. [CrossRef]

41. Khawla, B.J.; Sameh, M.; Imen, G.; Donyes, F.; Dhouha, G.; Raoudha, E.G.; Oumèma, N.-E. Potato peel as feedstock for bioethanol production: A comparison of acidic and enzymatic hydrolysis. Ind. Crop. Prod. 2014, 52, 144-149. [CrossRef]

42. Bai, D.-M.; Wei, Q.; Yan, Z.-H.; Zhao, X.; Li, X.-G.; Xu, S.-M. Fed-batch fermentation of Lactobacillus lactis for hyper-production of L-lactic acid. Biotechnol. Lett. 2003, 25, 1833-1835. [CrossRef]

43. Hickey, M.W.; Hillier, A.J.; Jago, G.R. Transport and metabolism of lactose, glucose, and galactose in homofermentative lactobacilli. Appl. Environ. Microbiol. 1986, 51, 825-831. [CrossRef] [PubMed]

44. Panesar, P.S.; Kennedy, J.F.; Gandhi, D.N.; Bunko, K. Bioutilisation of whey for lactic acid production. Food Chem. 2007, 105, 1-14. [CrossRef]

45. Yebra, M.J.; Martínez, G.P. Cross-talk between the L-sorbose and D-sorbitol (D-glucitol) metabolic pathways in Lactobacillus Casei. Microbiology 2002, 148, 2351-2359. [CrossRef] [PubMed]

46. Ge, X.-Y.; Qian, H.; Zhang, W.-G. Enhancement of L-lactic acid production in Lactobacillus Casei from Jerusalem artichoke tubers by kinetic optimization and citrate metabolism. J. Microbiol. Biotechnol. 2010, 20, 101-109. [CrossRef] [PubMed]

47. Kelkar, S.T.; Mahanwar, P.A. Production of lactic acid from tamarind kernel by Lactobacillus Casei. Int. J. Technol. Enhanc. Emerg. Eng. Res. 2010, 3, 25-31.

48. Cui, F.; Li, Y.; Wan, C. Lactic acid production from corn stover using mixed cultures of Lactobacillus rhamnosus and Lactobacillus brevis. Bioresour. Technol. 2011, 102, 1831-1836. [CrossRef] 